\title{
Effect of Nursing Teaching Guidelines Among Patients with Cirrhosis on Their Knowledge Regarding Minimizing Hepatic Encephalopathy
}

\author{
Manal Sayed Atya ${ }^{1}$, Mimi Mohamed Mekkawy ${ }^{2}$, Mohamed Omar Abd El-malek ${ }^{3}$ \& Asmaa Sayed Abd - \\ Almeged 4 . \\ 1. Assistant lecturer in Medical Surgical Nursing Department, Faculty of Nursing, Assiut University, Egypt. \\ 2. Professor of Medical Surgical Nursing, Faculty of Nursing, Assiut University, Egypt. \\ 3. Assistant Professor of Tropical Medicine and Gastroenterology, Faculty of Medicine, Assiut University, Egypt. \\ 4. Assistant Professor of Medical Surgical Nursing, Faculty of Nursing, Assiut University, Egypt.
}

\begin{abstract}
Background: Hepatic encephalopathy is a neuropsychiatric complication associated with liver cirrhosis. It occurs in up to $80 \%$ of patients with cirrhosis. Aim: To evaluate effect of nursing teaching guidelines on patients' knowledge regarding minimizing hepatic encephalopathy. Research design: Pre/post-test research design was utilized. Setting The study was conducted at Tropical Medicine and Gastroenterology department at El - Rajhi liver Hospital. Subjects and Methods: Thirty adult patients with liver cirrhosis. Tool: Structured interview questionnaire was utilized for data collection with three parts (sociodemographic, medical data and pre/post knowledge questionnaire). Results: The present study revealed that there was a highly statistically significant difference in the level of knowledge before, immediately post and after three months from application of nursing teaching guidelines. There was no statistically significant relation was documented between patient's knowledge and occurrence of hepatic encephalopathy, ascites and bleeding after three months from application of nursing teaching guidelines. Conclusion: It was concluded that level of knowledge regarding minimizing hepatic encephalopathy was improved after application of the nursing teaching guidelines. Recommendations: A written teaching guidelines hand book in simplified term should be available and distributed for cirrhotic patients about preventive measures of hepatic encephalopathy.
\end{abstract}

\section{Key Words: Nursing Teaching Guidelines, Knowledge \& Hepatic Encephalopathy.}

\section{Introduction}

Hepatic encephalopathy (HE) is a neuropsychiatric complication commonly associated with liver disease, namely cirrhosis. The inability of the liver to metabolize ammonia results in a buildup of ammonia, which can cross the blood-brain barrier and cause significant neurocognitive impairment. Up to $80 \%$ of patients with cirrhosis will experience $\mathrm{HE}$ and a large proportion of these patients are at high risk of recurrent HE (Flamm, 2018).

Prevention of hepatic encephalopathy is done through maintaining a proper nutrition, avoidance of precipitating factors (prevention of constipation, management of GIT bleeding and prevention of infection), good monitoring of intake and output, as a precaution administration of lactulose so that the bowel remain open and poor chance for ammonia to be absorbed, compliance with treatment and follow up (Shah et al., 2016). Providing structured information for the understanding of $\mathrm{HE}$ might be relevant to the prevention and management of the syndrome (Garrido et al., 2017).

Education is a critical component of any healthcare intervention; it has been found to improve treatment adherence, facilitate effective decision making, reduce healthcare costs and improve health outcomes. Nurses in their day to day contact with patients have the best opportunity to asses potential problems, discuss medical regimens and give teaching about all aspects of care, these include maintaining physical activity, recognizing activity limitations, conserving energy, following dietary modification and adhering to medication schedule, in addition to maintaining life style changes that best suit those patients (Valery et al., 2015).

Good patient education has proven to be a key tool in disease management, providing significant benefit in knowledge and behavioral modifications. It has been shown that the wide variation in patient knowledge may affect patients' willingness to accept and adhere to medical interventions (Shah and Abu-Amara, 2013).

Planning short and simple educational programs has a significant effect on the patient's control of his disease and its side effects; and can improve quality of life, life satisfaction, and mechanisms of coping with treatment (Noghabi et al., 2010).

\section{Significance of the study}

According to hospital registry at Tropical Medicine and Gastroenterology department at El Rajhi liver Hospital there were about 940 patients diagnosed with liver cirrhosis and about 200 patient diagnosed as hepatic encephalopathy were admitted in 2016. 
The researcher had observed from clinical experience that liver cirrhosis patients have lack of knowledge about complications of liver cirrhosis especially hepatic encephalopathy. Nurses play an important role in the assessment of patient's knowledge and teaching them to have better outcomes, so there is a definite need for health education in patients with cirrhosis regarding the risk of hepatic encephalopathy and its prevention.

\section{Aim of the study}

To evaluate the effect of nursing teaching guidelines on improving patient's knowledge regarding

minimizing hepatic encephalopathy.

\section{Research Hypothesis:}

The current study hypothesized that level of patients knowledge regarding minimizing hepatic encephalopathy will be improved after application of the nursing teaching guidelines.

\section{Subjects \& Methods \\ Research design:}

Pre / post-test research design was utilized in this study.

\section{Technical design}

\section{Setting}

The study was conducted in the Tropical Medicine and Gastroenterology department at El - Rajhi liver Hospital in Assuit University hospital.

\section{Subjects}

Thirty adult patients from both sexes, with child B or $\mathrm{C}$ liver cirrhosis who were willing to participate in the study their mean age was $59.16 \pm 6.046$ years old. The sample size was determined statistically by power analysis. The calculation was done considering the following: Type I error with significant level $(\alpha)$ $=0.5$, Type II error by power test $(1-\mathrm{B})=80 \%$ and found the minimum sample size was 24 patients. Although the minimum number of 24 patients was required by power analysis, the researcher had obtained 30 patients in this study because nonresponse rate was expected to be lost from the subjects.

\section{Tool for data collection}

\section{A structured patient interview questionnaire}

It was developed by the researcher after reviewing literature to assess characteristics of liver cirrhosis patients. It is consisted of the following three parts: Part (one): Socio-demographic data for the patient as (name, age, gender, marital status, residence, level of education, occupation).

Part (two): Medical data included (etiology of liver cirrhosis, history of other chronic diseases, presence of bleeding, esophageal varices, ascites, jaundice, essential medication data and laboratory investigations).
Part (three): Pre /post knowledge questionnaire:

It was developed by the researcher to assess patient's knowledge about hepatic encephalopathy. It was developed after reviewing the related literature. This part was applied by the researcher who asked the patients and then writing down their answers. This part was assessed (pre / immediately post and after three months) from application of nursing teaching guidelines.

It included (4) closed ended questions \& (11) open ended questions for the assessment of patient's knowledge about hepatic encephalopathy as (definition, risk factors, signs and symptoms, diagnostic studies, preventive measures, dietary restrictions, precautions for minimizing oesophageal varices bleeding, prevention of constipation, signs and symptoms of peritonitis and signs and symptoms of gastrointestinal bleeding).

Scoring system

The total number of questions were 15 questions, according to the (4) closed questions each question had one score for the correct answer and zero for the incorrect or I don't know answer. According to the open ended questions three responses from $0-2$ and divided as:

$>0 \rightarrow$ incorrect or I don't know.

$>1 \rightarrow$ incomplete correct.

$>2 \rightarrow$ complete correct.

The total knowledge score $(26$ degree $)$ was categorized into three categories

$>$ Low $<50 \%$.

$>$ Fair $50 \%-<70 \%$

$>\operatorname{Good} \geq 70 \%$.

Procedure

This study was carried out in three phases:

I-Preparatory phase

During this phase the researchers conducted the assessment process for the number of cases admitted in the Tropical medicine and Gastroenterology department at El- Rajhi liver hospital.

The research was approved from faculty of nursing ethics committee. An official letter was issued from the Dean of the Faculty of Nursing to the Head of Tropical medicine and Gastroenterology department at El- Rajhi liver hospital explaining the purpose of the study and requesting their permission for collecting the data.

A review of current and past, local and international related literature in the various aspects using books, articles, periodicals and magazines were done. The nursing instructions guidelines were prepared in simple Arabic language with simple photo illustrations.

Content validity was done by 5 expertise ( 2 medical staff from Tropical medicine and Gastroenterology department) \& (3 nursing staff) from the medical- 
surgical nursing field who reviewed the tool for clarity, relevance, comprehensiveness, understanding and applicability. Minor modifications were required and correction was carried out accordingly. As for the reliability the tool were confirmed for consistency by cronbach's alpha coefficient (alpha $=0.829$ ).

A Pilot study was conducted on $10 \%$ of sample ( 3 patients) admitted to the Tropical Medicine and Gastroenterology department at El - Rajhi liver Hospital in Assuit University to test the applicability and clarity of the tool. Obtained results used as a guide to reconstruct the changes needed in the data collection tool and those patients were excluded from the study sample.

\section{II- Implementation phase}

The collection of data and application of the nursing teaching guidelines lasted through the period from January 2018 to June 2018. Once permission was granted to proceed with the proposed study, the investigator initiated data collection, name of potential patients who have admitted to the unit and who met the criteria were obtained from computerized system.

First, the researcher greeted the patients, introduced herself and purpose of study was explained by the researchers to patients who agreed to participate in the study prior to any data collection. The researcher took the patients' telephone number at the first contact (During hospitalization) to determine the time of appointments in order to complete data collection process (after three months).

After taking the patient oral agreement for voluntary participation in the study, the researcher filled the data collection tool with the patients at three intervals (pre, then immediately post and after three months) from the initial assessment. Pre assessment involved assessment of patients' demographic characteristics, clinical data and knowledge regarding minimizing hepatic encephalopathy.

Then the researcher explained the nursing teaching guidelines which were developed by the researcher after passing through an extensive and relevant literature review. Its aim was to enable patients who had liver cirrhosis to be knowledgeable about guidelines which help them in minimizing risk of hepatic encephalopathy. It was prepared in simple Arabic language with simple photo illustrations. It was covered the following:

$\&$ Brief overview about anatomy of liver.

$\varangle$ Functions of liver.

$\&$ Brief overview about liver cirrhosis.

$\&$ Information about hepatic encephalopathy disease as (definition, risk factors, signs \& symptoms and diagnostic studies).
$<$ Nursing teaching guidelines to minimize hepatic encephalopathy as (maintaining proper nutrition, prevention of precipitating factors and importance of compliance to therapeutic regimen).

Each patient was met for one session in the morning shift. The session took about 20-30 minutes. Patients were allowed to ask questions in case of misunderstanding while listening and expressing interest. After the session there were about 5-10 minutes for discussion and feedback. Reinforcement was performed according to patient's needs to ensure their understanding. One family member was present in the session for patient support.

Each patient obtained a copy of the booklet in a clear Arabic language also the researcher used pictures to enhance patient's knowledge and helped them to retain the learned material.

At the end of the session the researcher emphasized to the patients the importance of follow up visits and arranged with them the time and place for follow up which was after three months.

\section{III- Evaluation phase}

Patients were evaluated for knowledge immediately post application of nursing teaching guidelines and attended the follow up session post three months in the Tropical medicine and Gastroenterology department at El- Rajhi liver hospital.

\section{Ethical consideration}

- Research proposal was approved from ethical committee in the faculty of nursing.

- An informed consent was obtained from patients to participate in the study and the nature and purpose of the study were explained to them.

- The researcher initially introduced herself to all optional subjects and they were assured that collected data would be absolutely confidential.

- They were informed that participation is voluntary and that they have the right to withdraw at any time of the study.

- Confidentiality of the patient's data was ascertained.

\section{Statistical design:}

Data entry was done using compatible personal computer by the researcher. All data was entered into statistical packages for the social sciences (SPSS) version 20.0 software for analysis and Excel for figures. The content of each tool was analysed, categorized and then coded by the researcher. Categorical variables were described by number and percent, where continuous variables described by mean and standard deviation (Mean, SD). Chi-square test and fisher exact test used to compare between categorical variables where compare between continuous variables by unpaired t-test. A two-tailed $\mathrm{p}<0.05$ was considered statistically significant. 


\section{Results}

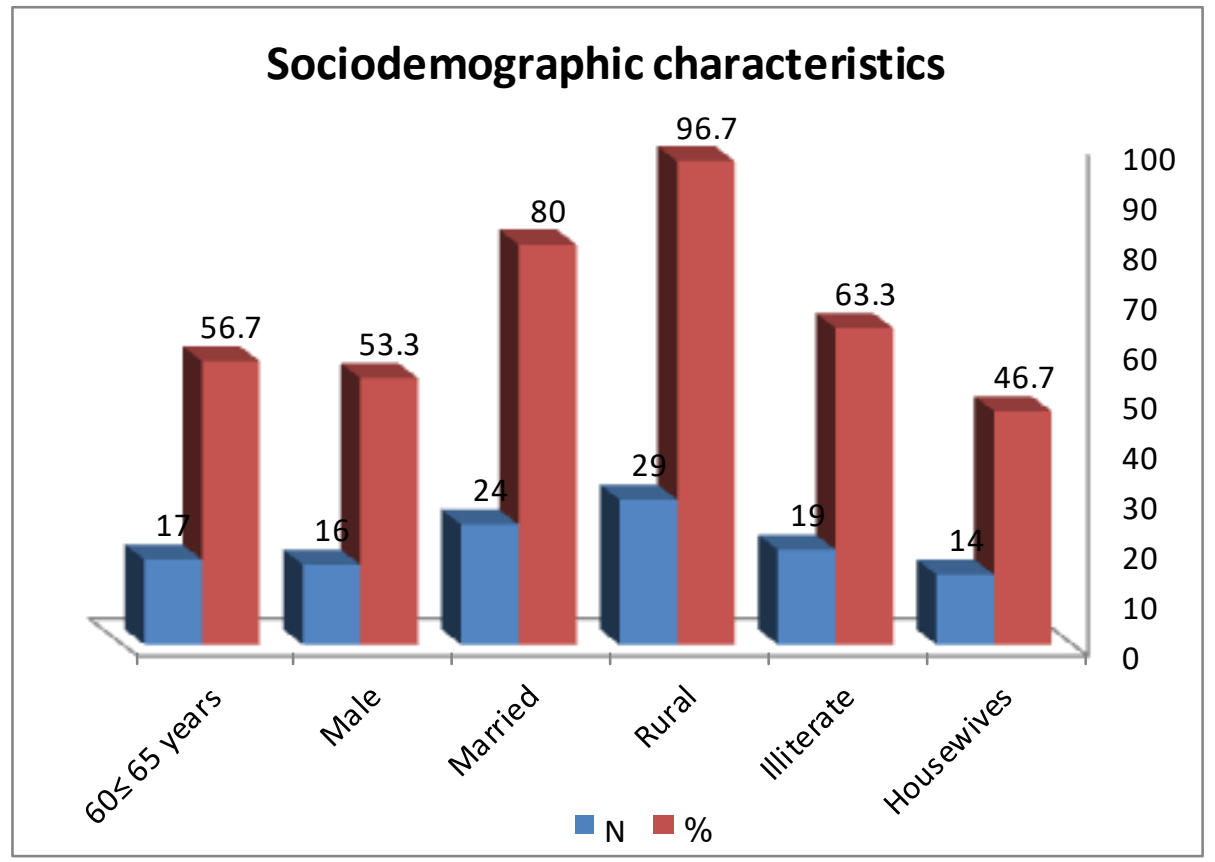

Figure (1): Sociodemographic characteristics of studied patients $(n=30)$.

Table (1): Distribution of studied patients as regarding to medical data $(n=30)$.

\begin{tabular}{|c|c|c|}
\hline Medical data & $\mathbf{N}$ & $\%$ \\
\hline \multicolumn{3}{|l|}{ Etiology of liver cirrhosis } \\
\hline - $\quad$ Hepatitis $\mathrm{C}$ virus & 24 & 80.0 \\
\hline - Hepatitis B virus & 2 & 6.7 \\
\hline - Un known cause & 4 & 13.3 \\
\hline \multicolumn{3}{|c|}{ History of other chronic diseases } \\
\hline \multicolumn{3}{|c|}{ Diabetes } \\
\hline Yes & 12 & 40.0 \\
\hline No & 18 & 60.0 \\
\hline \multicolumn{3}{|l|}{ Renal disease } \\
\hline No & 30.0 & 100.0 \\
\hline \multicolumn{3}{|l|}{ Hypertension } \\
\hline Yes & 8 & 26.7 \\
\hline No & 22 & 73.3 \\
\hline \multicolumn{3}{|l|}{ Cancer(HCC or others) } \\
\hline Yes & 7 & 23.3 \\
\hline No & 23 & 76.7 \\
\hline
\end{tabular}


Table (2): Distribution of studied patients as regarding to present health history $(n=30)$.

\begin{tabular}{|c|c|c|}
\hline Present health history & $\mathbf{N}$ & $\%$ \\
\hline \multicolumn{3}{|l|}{ Bleeding } \\
\hline - Yes & 16 & 53.3 \\
\hline - $\quad$ No & 14 & 46.7 \\
\hline \multicolumn{3}{|l|}{ If yes what is the type } \\
\hline - Hematemesis & 5 & 29.2 \\
\hline - Melena & 3 & 20.8 \\
\hline - Both & 8 & 50.0 \\
\hline \multicolumn{3}{|l|}{ Esophageal varices } \\
\hline - Yes & 15 & 50.0 \\
\hline - $\mathrm{No}$ & 15 & 50.0 \\
\hline \multicolumn{3}{|l|}{ If yes the management is } \\
\hline - Endoscopic band ligation & 10 & 66.7 \\
\hline - None & 5 & 33.3 \\
\hline \multicolumn{3}{|l|}{ Ascites } \\
\hline - Yes & 24 & 80.0 \\
\hline - No & 6 & 20.0 \\
\hline \multicolumn{3}{|c|}{ If yes the degree (Based on physical examination and abdominal ultrasound) } \\
\hline - Mild & 7 & 29.2 \\
\hline - Moderate & 8 & 33.3 \\
\hline - Tense & 9 & 37.5 \\
\hline \multicolumn{3}{|l|}{ Jaundice } \\
\hline - Yes & 19 & 63.3 \\
\hline - No & 11 & 36.7 \\
\hline
\end{tabular}

Table (3): distribution of studied patients regarding knowledge level (pre, immediately post and after three months) from application of nursing teaching guidelines $(n=30)$.

\begin{tabular}{|l|c|c|c|c|c|c|c|}
\hline \multirow{2}{*}{ Knowledge } & \multicolumn{2}{|c|}{ Pre } & \multicolumn{2}{c|}{ Immediately } & \multicolumn{2}{c|}{ Post three months } & \multirow{2}{*}{ P.value } \\
\cline { 2 - 7 } & $\mathbf{N}$ & $\mathbf{\%}$ & $\mathbf{N}$ & $\mathbf{\%}$ & $\mathbf{N}$ & $\mathbf{\%}$ & \\
\hline Low & 29 & 96.7 & 0 & 00.0 & 0 & 00.0 & \\
Fair & 1 & 3.3 & 0 & 00.0 & 3 & 10.0 & \multirow{2}{*}{$0.001 * *$} \\
\hline Good & 0 & 00.0 & 30 & 100.0 & 27 & 90.0 & \\
\hline Mean \pm SD & \multicolumn{2}{|c|}{$4.86 \pm 2.97$} & \multicolumn{2}{|c|}{$23.13 \pm 1.88$} & \multicolumn{2}{|c|}{$20.60 \pm 2.82$} & \\
\hline
\end{tabular}

One way anova test $\quad * *=$ highly statistical significant

Table (4): Relation between mean knowledge score level of the studied patients (pre, immediately post and after three months from application of nursing teaching guidelines and their sociodemographic characteristics $(n=30)$.

\begin{tabular}{|l|c|c|c|c|}
\hline \multirow{2}{*}{$\begin{array}{c}\text { Sociodemographic } \\
\text { Characteristics }\end{array}$} & \multirow{2}{*}{$\mathbf{N}$} & \multicolumn{2}{c|}{ Knowledge (One-way Anova - Independent T- test) } \\
\cline { 3 - 5 } & & Pre & Immediately & Post three months \\
\cline { 3 - 5 } & & Mean \pm SD & Mean \pm SD & Mean \pm SD \\
\hline Age & 1 & & & $19.00 \pm----$ \\
\hline 30<40years & 12 & $5.0 \pm----$ & $23.00 \pm------$ & $21.08 \pm 2.77$ \\
\hline 50<60 years & 17 & $4.76 \pm 3.25$ & $23.00 \pm 2.17$ & $20.35 \pm 2.95$ \\
\hline 60:65 years & & $\mathbf{0 . 9 7 9}^{\mathbf{N s}}$ & $\mathbf{0 . 8 8 8} \mathbf{N s}^{\mathbf{N s}}$ & $\mathbf{0 . 6 8 5}$ \\
\hline P. value & & & & $21.43 \pm 2.68$ \\
\hline Gender & 16 & $6.12 \pm 3.46$ & $23.53 \pm 1.80$ & \\
\hline Male & &
\end{tabular}




\begin{tabular}{|c|c|c|c|c|}
\hline \multirow{3}{*}{$\begin{array}{c}\text { Sociodemographic } \\
\text { Characteristics }\end{array}$} & \multirow{3}{*}{$\mathbf{N}$} & \multicolumn{3}{|c|}{ Knowledge (One-way Anova - Independent T- test) } \\
\hline & & Pre & Immediately & Post three months \\
\hline & & Mean \pm SD & Mean \pm SD & Mean \pm SD \\
\hline Female & 14 & $3.42 \pm 1.34$ & $22.71 \pm 1.93$ & $19.64 \pm 2.76$ \\
\hline P. value & & 0.011* & $0.249^{\mathrm{Ns}}$ & $0.082^{\mathrm{Ns}}$ \\
\hline \multicolumn{5}{|l|}{ Marital Status } \\
\hline Married & 24 & $5.33 \pm 3.14$ & $23.39 \pm 1.64$ & $21.08 \pm 2.61$ \\
\hline Widow or widower & 6 & $3.00 \pm .89$ & $22.16 \pm 2.56$ & $18.66 \pm 3.01$ \\
\hline P. value & & $0.086^{\mathrm{Ns}}$ & $0.160^{\mathrm{Ns}}$ & $0.059 *$ \\
\hline \multicolumn{5}{|l|}{ Residence } \\
\hline Urban & 1 & $15.00 \pm----$ & $26.00 \pm-----$ & $25.00 \pm----$ \\
\hline Rural & 29 & $4.51 \pm 2.32$ & $23.03 \pm 1.83$ & $20.44 \pm 2.74$ \\
\hline P. value & & $0.000 * *$ & $0.124^{\mathrm{Ns}}$ & $0.144^{\mathrm{Ns}}$ \\
\hline \multicolumn{5}{|l|}{ Level of education } \\
\hline Illiterate & 19 & $3.84 \pm 1.30$ & $22.61 \pm 1.64$ & $19.94 \pm 2.73$ \\
\hline Preparatory school & 4 & $3.75 \pm 1.70$ & $23.00 \pm 2.44$ & $20.00 \pm 2.94$ \\
\hline Secondary school & 2 & $5.00 \pm 1.41$ & $23.00 \pm 1.41$ & $21.50 \pm .707$ \\
\hline University & 5 & $9.60 \pm 4.44$ & $25.20 \pm 1.30$ & $23.20 \pm 2.48$ \\
\hline P. value & & $0.000 * *$ & 0.049* & $0.126^{\mathrm{Ns}}$ \\
\hline \multicolumn{5}{|l|}{ Occupation } \\
\hline Employer & 6 & $6.16 \pm 3.54$ & $24.16 \pm 1.83$ & $22.66 \pm 3.01$ \\
\hline House wife & 14 & $3.42 \pm 1.34$ & $22.71 \pm 1.93$ & $19.64 \pm 2.76$ \\
\hline Not work & 7 & $5.00 \pm .81$ & $22.50 \pm .547$ & $19.71 \pm 1.38$ \\
\hline Retired & 3 & $8.66 \pm 6.50$ & $24.33 \pm 2.88$ & $23.00 \pm 2.64$ \\
\hline P. value & & $0.017 *$ & $0.266^{\mathrm{Ns}}$ & $0.043 *$ \\
\hline
\end{tabular}

Table (5): Relation between mean knowledge score of the studied patients and occurrence of hepatic encephalopathy, GIT bleeding and ascites after three months from application of nursing teaching guidelines $(\mathbf{n}=\mathbf{3 0})$.

\begin{tabular}{|l|c|c|c|}
\hline \multicolumn{1}{|c|}{ Variables } & N & Mean knowledge \pm SD & P.value \\
\hline Hepatic encephalopathy & 25 & $20.76 \pm 3.04$ & \multirow{2}{*}{$0.503^{\mathrm{NS}}$} \\
\cline { 1 - 3 } & 5 & $19.80 \pm 1.09$ & \\
\hline Yes & 24 & $20.46 \pm 2.83$ & $0.473^{\mathrm{NS}}$ \\
\hline GIT bleeding & 6 & $21.50 \pm 3.00$ & \\
\hline No & \multicolumn{3}{|c|}{$0.497^{\mathrm{NS}}$} \\
\hline Yes & 23 & $21.28 \pm 2.81$ & \\
\hline Ascites & 7 & $20.39 \pm 2.85$ & \\
\hline No & \multicolumn{3}{|l|}{} \\
\hline Yes &
\end{tabular}

Ns = non-significant difference

Figure (1): Shows that more than half of studied patients were male and their age was ranged from 60 to less than $65(56.7 \%, 53.3 \%)$ respectively. As regarding marital status and residence it was found that the highest percentages of patients were married and residents in rural areas $(80.0 \%, 96.7 \%)$ respectively. Regarding to educational level and occupation it was found that $(63.3 \%, 46.7 \%)$ of studied patients were illiterate and were housewives respectively.
Table (1): Shows that hepatitis $C$ virus was the main cause of cirrhosis in the highest percentage of patients $(80.0 \%)$. As regarding presence of chronic diabetes mellitus was documented in (40\%), hypertension in $(26.7 \%)$ and cancer (HCC or others) in $(23.3 \%)$ of patients while all of studied patients hadn't renal disease.

Table (2): Illustrates that more than half (53.3\%) of studied patients had gastrointestinal bleeding half of them had both hematemesis and melena. More than half $(51.7 \%)$ of studied patients had oesophageal 
varices and more than two third of them (66.7\%) had performed endoscopic band ligation. The majority $(80.0 \%)$ of patients had ascites more than one third $(37.5 \%)$ of them had tense ascites. Nearly two thirds $(63.3 \%)$ of patients had jaundice.

Table (3): Shows that the highest percentage of patients $(96.7 \%)$ had low level of knowledge pre application of nursing teaching guidelines, while all of them had good level of knowledge immediately post application of nursing teaching guidelines and the highest percentage $(90.0 \%)$ of studied patients also had good level of knowledge after three months from application of nursing teaching guidelines with highly statistical significant difference $(\mathrm{p}<0.001)$.

Table (4): Shows that there was a significant statistical relation between patient's knowledge and gender, residence, education and occupation pre application of nursing teaching guidelines. A significant difference was observed between knowledge and educational level immediately post application of nursing teaching guidelines and between marital status and occupation post three months.

Table (5): Shows that there was no statistically significant relation was documented between patient's knowledge and occurrence of hepatic encephalopathy, GIT bleeding and ascites after three months from application of nursing teaching guidelines.

\section{Discussion}

Regarding socio-demographic characteristics of the patients; the current study pointed out that; more than half of the patients were aged from sixty to less than sixty five and the mean age was 59.16 \pm 6.04 years. These findings agreed with a study conducted by Hayward et al., (2017) and reported that the mean age of patients was $58.4 \pm 10.2$ years.

The results from data collected in this study showed that slightly more than half of patients were male. This result was congruent with Al Ghamdi \& Shah, (2018) who reported in their study that more than half of patients were male. Similar to present study results a study conducted by EL-Shafei et al., (2017) and revealed that slightly more than two thirds of patients were male.

In relation to marital status the present study revealed that the majority of patients were married. According to occupation the present study revealed that all of female patients were housewives and the highest percentages of male patients were non workers. As regarding to educational level around two thirds of them were illiterate. This study finding was in line with a study conducted at Internal Medical Department in Minia University Hospital by Taha et al., (2015) which revealed that the majority of both study and control group patients were married, housewives, and illiterate.

As regards to the place of residence, results from data collected in this study showed that the majority of patients were residents in rural areas these finding was supported by Khalil et al., (2015) who reported that highest percentage of patients lived in rural area.

Regarding to medical data; the results of the present study revealed that, the majority of patients had diagnosed with hepatitis $\mathrm{C}$ as a cause for liver cirrhosis. This result agrees with a study conducted by Kamal et al., (2018) \& Jamil \& Durrani, (2018) who reported that the most common cause of hepatic cirrhosis in their study population was chronic infection with hepatitis $\mathrm{C}$.

Likewise Ali et al., (2014) supported the previous finding as they stated that majority of patients had cirrhosis due to chronic hepatitis $\mathrm{C}$. On the other hand this finding contradicted by Handady et al., (2015) who reported that regarding etiology of liver cirrhosis nearly half of cases had viral hepatitis B.

As regarding presence of chronic diseases the present study documented that diabetes mellitus, hypertension and cancer were present in minority of patients and all of studied patients hadn't renal disease. In agreement with present results Kuo et al., (2017) who conducted a study for liver cirrhosis patients who waiting liver transplantation and reported that regarding to medical co-morbidities: $48 \%$ of patients had hypertension, $28 \%$ of patients had diabetes, and $6 \%$ of patients had coronary artery disease. Similarly Chang et al., (2015) agree with these findings as they reported that diabetes mellitus, hyperlipidemia and hypertension were present in more than one third of patients while renal impairment was documented in minority.

Regarding present health history; the present study revealed that more than half of patients had gastrointestinal bleeding half of them had both hematemesis and melena. Slightly more than half of patients had oesophageal varices and two thirds of them had performed endoscopic band ligation. These findings were supported by Abd Elkader et al., (2014) who reported that nearly half of patients presented with hematemsis \& melena but disagree with method of treatment as stated that concerning management of esophageal varices more than half of patients were treated by variceal injection and band ligation. The same result was supported by Garcia-Tsao et al., (2017) who stated that gastro esophageal varices are present in approximately $50 \%$ of patients with cirrhosis. In patients with compensated cirrhosis these are present in 30\%-40\%, whereas they can be present in up to $85 \%$ of patients with decompensated cirrhosis. 
Study results represented that, the majority of studied patients had ascites; slightly more than one third had tense ascites and one third of them had moderate ascites. This finding was in line with Abdel Rehaim \& Mohamed, (2017) who reported that the majority of the study group had moderate degree of ascites while the minority from them had mild degree of ascites. The same result was supported by James and Liou., (2015) \& Cesario et al., (2011) who reported that ascites is a common complication of cirrhosis and it is an important landmark in the natural history of chronic liver disease.

The present study revealed that the highest percentage of studied patients had jaundice. Wasim et al., (2014) support this result as they mentioned that the most common signs and symptoms which was found in cirrhotic patients are weight loss and anorexia in $(100 \%)$, jaundice in $(90.5 \%)$, fatigue and weakness in $(89.2 \%)$.

Also similar to present results Nayak et al., (2016) agree with the previous results who revealed that; jaundice was documented in $72 \%$ of patients and ascites in $66 \%$ and they were the most common presenting features in this study.

\section{Concerning patients' knowledge about hepatic encephalopathy}

The current study revealed a great lack of patient's knowledge as regard hepatic encephalopathy pre implementation of the nursing teaching guidelines. This finding could be attributed to their formal education background that may be a factor as nearly two thirds of patients were illiterate. Also this lack of knowledge would be attributed to the lack of opportunity to be educated about hepatic encephalopathy prevention. This finding supported by Volk et al., (2013) who found that cirrhosis patients lack adequate knowledge about important information needed to self-manage their disease. Results of the current study showed that there was an obvious improvement in total mean knowledge scores of the studied patients immediately post and after three months from application of nursing teaching guidelines. This may be attributed to theoretical sessions that were provided to patients which cover all aspects of hepatic encephalopathy and the provision and explanation of the nursing teaching guidelines. Weheida et al., (2009) were in the same line as they reported that there were an improvement in the total mean knowledge scores of study patients pre, immediately post intervention and three months post discharge. In accordance with our results Mahmoud et al., (2013) support this finding as they stated that the patients' knowledge was improved after the educational program. All of patients knew the complications of cirrhosis, allowed and prohibited food and drugs after the program.

Likewise Taha et al., (2015) pointed that the highest mean knowledge score was after implementation of the nursing intervention protocol in study group compared to control group and show high statistical significant differences in the study group.

Also the previous finding was supported by Goldsworthy et al., (2017) as they demonstrated that patient understanding of liver cirrhosis is poor. The delivery of relevant information led to a significant improvement in patients' knowledge about their condition.

Also these findings supported by Volk et al., (2013) who reported that patient knowledge, or at least their ability to access the necessary information, was improved by a simple educational intervention and providing a concise booklet and emphasizing its importance was associated with a $26 \%$ improvement in patient knowledge.

The same finding was in accordance with Garrido et al., (2017) who confirmed limited disease awareness in patients with a history of hepatic encephalopathy also they reported that after the intervention, $70 \%$ of patients had acquired new information about the pathophysiology of $\mathrm{HE}$, and $80 \%$ of them had improved their knowledge about HE prevention/treatment.

Regarding relation between patients mean knowledge scores and their sociodemographic characteristics; the present study showed that the higher educational degree, male patients, retired, married and living in urban community were significantly associated with higher knowledge scores. This could be due to that the highly educated and urban patients have good access to new technology from which they could gain a lot of information regarding their disorder. And educational level increase in people's alertness about importance of being knowledgeable and what should be done to maintain or enhance their health. These findings was in the same line with Al-Johani et al., (2018) who reported that there was a positive significant association between high level education and good awareness about cirrhosis of liver. Also Abbas et al., (2015) were in the same line as they mentioned that educational level was associated with a greater knowledge ( $\mathrm{P}$ value $<0.05$ ). According to the retired patients this might be due to their unwillingness to take risks related to their health. Besides, those patients might have a greater awareness of mortality and thus have a stronger motivation to be more knowledgeable to their condition.

According to marital status which had effect on improving knowledge this can be attributed that it is likely that people who have a spouse may exhibit 
higher knowledge because of support and encouragement that provided to them from their partner regarding importance of following guidelines to avoid complications which can effect on their lives.

Regarding relation between patients mean knowledge scores and medical data; the present study showed that in spite of decrease numbers of patients who compliant of bleeding and ascites post three months there was no statistically significant relation was documented between mean knowledge and occurrence of these complications and similarly in regard to patients who exposed to hepatic encephalopathy post three months. This may be explained by although well-informed patients could have avoided precipitant factors such as constipation or dehydration, factors such as infection or bleeding are obviously more difficult to prevent/control.

This finding was in line with Mahdy et al., (2018) who reported that there were no statistically significant relation between patients' total knowledge and recurrent bleeding in the study and control group post- and follow up guidelines intervention in spite of the mean score of knowledge of patients in the control group is less than in the study group post- and follow up guidelines intervention.

\section{Conclusion}

The study findings supported the research hypothesis as it had been proven that there was highly statistical significant difference was documented in the level of knowledge pre and post application of nursing teaching guidelines.

\section{Recommendations}

Based on the findings of present study, the following recommendations are suggested:

\section{For patients}

- Continuous schedule programs to improve patient's knowledge about hepatic encephalopathy, its prevention and early detection.

- Encourage patients to participate in group teaching regarding hepatic encephalopathy.

- Establishment of a web site, including all information pertained to hepatic encephalopathy and all aspect of health education such as different educational materials, Medias and audio-visual aids. Establishment of a hot line (phone and net) contact for urgent consultations.

\section{For nurses}

- Periodically assessment of nurses' knowledge in relation to liver cirrhosis and its complications.

- In-service training programs should be conducted on regular basis to improve and up-date nurses' knowledge and practice.
- The discharge planning process needs to be stated clearly for nurses and they should be aware by their professional responsibilities.

\section{For administration}

- Schedule vaccination programs for hepatitis B patients.

- Ward conference should be planned periodically in order to introduce to all health team members new advice in the field for their provision of care.

- A written teaching hand book should be available for each patient in simplified term and containing simple pictures and distributed among cirrhotic patients about preventive measures of hepatic encephalopathy to provide them with the needed information.

- Engagement of patient care providers in treatment, clinical management and patient education sessions is recommended to improve and sustain adherence levels.

\section{For research}

- Replication of the study on a larger probability sample selected from different geographical areas in Egypt is recommended to obtain more generalizable data.

\section{References}

1. Abbas, A., Kachela, B., Arif, J., Tahir, K., Shoukat, N., \& Ali, N., (2015): Assessment of medication adherence and knowledge regarding the disease among ambulatory patients with diabetes mellitus in Karachi, Pakistan. Journal of Young Pharmacists, 7(4), 328-340.

2. Abd Elkader, A., El Sebaee, H., \& El Sayed, Z., (2014): Patients' knowledge assessment regarding factors aggravating esophageal variceal bleeding at a university hospital in Egypt, Advances in Life Science and Technology, volume(23). PP 32-42.

3. Abdel Rehaim1, J., \& Mohamed, I., (2017): Knowledge of Patient with Liver Cirrhosis Regarding Ascites Self-Management: Instructions Nursing Guidelines. Journal of Nursing and Health Science Volume 6, Issue 4 P.p 88-95.

4. Al Ghamdi, S., \& Shah, H., (2018): An Educational Needs Assessment for Patients with Liver Disease. Journal of the Canadian Association of Gastroenterology, 1(2), 54-59.

5. Ali, B., Zaidi, Y., Alam, A., \& Anjum, H., (2014): Efficacy of rifaximin in prevention of recurrence of hepatic encephalopathy in patients with cirrhosis of liver. J Coll Physicians Surg Pak, 24(4), 269-273.

6. Al-Johani, J., Aljehani, S., Alzahrani, G., (2018): Assessment of Knowledge about Liver 
Cirrhosis among Saudi Population. The Egyptian Journal of Hospital Medicine, Vol (71), issue (2), Pp. 2443-2446.

7. Cesario, K., Choure, A., \& Carey, W., (2011): Complications of Cirrhosis: ascites, Hepatic Encephalopathy, and Variceal Hemorrhage, the Cleveland Clinic Foundation, Center for Continuing Education, pp (555-558) .

8. Chang, P., Wong, G., Li, J., Lui, H., Chow, W., \& Tan, C., (2015): Epidemiology and clinical evolution of liver cirrhosis in Singapore. Annual Academy of Medicine Singapore, 44(6), 218-225.

9. EL-Shafei, A., EL-Tiby, D., Abdelaziz, S., Abdel Fatah, A., \& Gaafar, A., (2017): prevalence of reflux esophagitis in Egyptian patients with liver cirrhosis, Journal of the Egyptian Society of Parasitology, Vol. 47, No. 2, P.p $433-441$.

10. Flamm, S., (2018): Considerations for the costeffective management of hepatic encephalopathy. The American journal of managed care, Vol 24, No (4) S51-S61.

11. Garcia-Tsao, G., Abraldes, J., Berzigotti, A., \& Bosch, J., (2017): Portal hypertensive bleeding in cirrhosis: Risk stratification, diagnosis, and management: 2016 practice guidance by the American Association for the study of liver diseases. Hepatology, 65(1), 310335.

12. Garrido, M., Turco, M., Formentin, C., Corrias, M., De Rui, M., Montagnese, S., \& Amodio, P., (2017): An educational tool for the prophylaxis of hepatic encephalopathy. BMJ Open Gastroenterology, 4(1), e000161. http://doi.org/10.1136/bmjgast-2017-000161.

13. Goldsworthy, M., Fateen, W., Thygesen, H., Aldersley, M., Rowe, L., \& Jones, R., (2017): Patient understanding of liver cirrhosis and improvement using multimedia education Frontline Gastroenterology, vol (8), P.p:214219.

14. Handady, S., Ahmed, M., Fadl, A., \& Alawad, A., (2015): Precipitating Factors of Hepatic Encephalopathy Among Sudanese Patients with Liver Cirrhosis, Medicine Journal. Vol. 2, No. 4, 2015, pp. 63-67.

15. Hayward, K., Valery, P., Martin, J., Karmakar, A., Patel, P., Horsfall, L., \& Irvine, K., (2017): Medication beliefs predict medication adherence in ambulatory patients with decompensated cirrhosis. World journal of gastroenterology, 23(40), Pp.7321-7331

16. James J., \& Liou I., (2015): Comprehensive care of patients with chronic liver disease. Med Clin North Am.2015; 99(5):913-933.
17. Jamil Z., \& Durrani A., (2018): Assessing the outcome of patients with liver cirrhosis during hospital stay: A comparison of lymphocyte/monocyte ratio with MELD and Child-Pugh scores. Turk J Gastroenterology, vol (29), Pp308-315.

18. Kamal, S., Abdelhakam, S., Massoud, Y., El Aziz Abd El Hafeez, K., \& Kamal, H., (2018): Clinical Profile of patients with Ascitic Fluid Infection at Ain Shams University Hospitals. Egyptian Journal of Hospital Medicine, Volume 72, Issue 9, P.p 5241-5250.

19. Khalil, S., El-Sayed Youssef, M., Mekkawy, M., \& Abd el-malek, M., (2015): Liver Cirrhosis: Effect of Suggested Nutritional Regimen on Patient Outcomes, Doctoral thesis, faculty of nursing, Assuit university.

20. Kuo, S., Haftek, M., \& Lai, J., (2017): Factors associated with medication nonadherence in patients with end-stage liver disease. Digestive diseases and sciences, 62(2), 543-549.

21. Mahdy N., Khorais, A., \& Abdelhamid R., (2018): Effect of Secondary Prevention Educational Guidelines on Patients' Clinical Outcomes Post Endoscopic Ligation of Esophageal Varies, IOSR Journal of Nursing and Health Science (IOSR-JNHS), vol. 7, no.3, pp. 05-20.

22. Mahmoud, F., Ebeid, N., \& Elaziz, M., (2013): The Impact of Self-Care Instructional program on Quality of Life of Patients with Liver cirrhosis at El-Kasr EL Ainy Cairo University Hospital, Nature and Science, vol (11), issue (6), P.p 95-105.

23. Nayak, M., Anubhaw, N., \& Nayak, R., (2016): Incidence of Hepatic Encephalopathy in Cirrhosis of Liver. International Journal of Contemporary Medical Research, Volume 3, Issue 12, Pp. 3528-3532.

24. Noghabi, A., Zandi, M., Mehran, A., Alavian, S., \& Dehkordi, A., (2010): Effect of Education on Quality of Life in Patients under Interferon Therapy, Hepatitis monthly, 10(3), 218-222.

25. Shah S., Shah P., \& Shah K., (2016): Prevention for cirrhosis of liver and its progression, $1^{\text {st }}$ ed, The health sciences publisher, London, p, 62 .

26. Shah, H., \& Abu-Amara, M., (2013). Education provides significant benefits to patients with hepatitis $\mathrm{B}$ virus or hepatitis $\mathrm{C}$ virus infection: a systematic review. Clinical Gastroenterology and Hepatology, 11(8), 922933. 
27. Taha, S., Mohamed, W., Bukhary, F., Teleb, S., Gamal, L., (2015): Impact of a Designed Nursing Intervention Protocol on quality of life for liver cirrhosis patients in Minia University Hospital . Journal of Nursing and Health Science, Volume 4, Issue 4, P.P 8898.

28. Valery, P., Powell, E., Moses, N., Volk, M., McPhail, S., Clark, P., \& Martin, J., (2015): Systematic review: unmet supportive care needs in people diagnosed with chronic liver disease. BMJ open, 5(4), e007451.

29. Volk, M., Fisher, N., \& Fontana, R., (2013): Patient Knowledge about Disease SelfManagement in Cirrhosis, American Journal of Gastroenterology, vol (108), no (3), Pp 20122014.

30. Wasim, M., Biland, B., Idrees, M., Zeb, M., Waqar, M., Khan, M., \& Faisal, S., (2014): Assessment of risk factors and clinical presentations in a liver cirrhotic state-Pakistan. World Applied Sciences Journal, 32(7), 12521257.

31. Weheida, S., Mohsen, M., Bahenasy, A., Shehata, A., \& Heneedy, W., (2009). Effect of protocol of care on clinical outcomes of patients with liver cirrhosis. Bull. Alex. Fac. Med, 45(3).Pp. 603- 616. 